Journal Home Page:

http://perlinguam.journals.ac.za

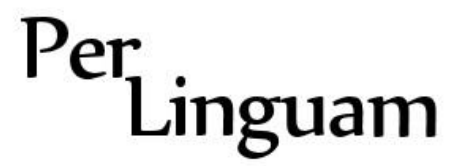

A Journal for Language Learning Tydskrif vir Taalaanleer

\title{
AN ANALYSIS OF THE TEXTUAL PRACTICES OF UNDERGRADUATE AND POSTGRADUATE NOVICE WRITERS IN LAW
}

\author{
Bongi Bangeni \\ Lesley Greenbaum \\ University of Cape Town
}

Criticisms in the media and in the law professions about the writing skills of law graduates have drawn attention to the challenges that novice law students experience in acquiring these skills at the foundation level. Our research project attempts to understand the nature of these challenges from multiple perspectives: firstly, by sourcing students' understandings of their challenges with legal writing through semi-structured interviews, followed by a close textual analysis of samples of their writing, as well as through feedback from teaching staff. In this paper, we present the findings of our textual analysis of their writing. We illustrate how their difficulties with legal writing manifest at the levels of content, concept and lexico-grammar and how the students' struggles with legal concepts had implications for their overall engagement with the content of the subject matter. At the level of content, students exhibited problems with the appropriate presentation of subject matter, achieving precision in their writing and showing evidence of an appreciation of what counts as tacit knowledge within the discipline, while at the lexico-grammatical level they struggled with tense, preposition and article use. The paper concludes by recommending some strategies for responding to these challenges while taking into account their resource implications.

\section{INTRODUCTION}

Media reports in recent years in South Africa have contained criticisms about the quality of university law (LLB) graduates. The complaints relate primarily to the writing and numeracy skills of these aspiring lawyers (see for example, Cape Times, 4 April, 2007; The Times, 5 July, 2012). These reports have necessitated an understanding of law students' struggles at the foundation level of their studies. The acquisition of legal writing skills represents a challenge to novice law students in that the conventions of writing within the discourse of Law represent a particular set of practices that are unfamiliar, requiring writers to master a set of not only good but also specialisd thinking and writing skills (Williams, 1991:13). In developing an understanding of the challenges faced by novice legal writers, it is notable that the grasp of legal language cannot be separated from the acquisition of new conceptual frameworks: 'Behind the form and lexis lies the tradition of the logic of the law - the concepts of issues, points of law, authority, opinion, decision and so on, arranged in a discourse peculiar to the subject...Students learn from the law tutor the language and the pattern of the argument at the same time as they learn law' (Howe, 1990:216). According to Maurer and Mischler (1994) the extent to which students are successful in engaging with these aspects of legal study in their first year of study is directly linked to their success upon entry into the legal profession. 
With these considerations in mind, the authors conducted a research project to ascertain the ways in which undergraduate and postgraduate novice law students perceive their writing skills as they are inducted into the discipline of Law, and to analyze samples of texts produced by them in their first year in the faculty. This analysis was undertaken to obtain a better understanding of particular difficulties evident in their writing and, in relation to Howe's (1990) statement, to gauge the extent to which they had acquired the language of law in their initial year in the faculty.

\section{METHODOLOGY}

This article draws on the findings yielded by a textual analysis of a data corpus comprising a law essay which students wrote in the first semester, in April, as well as a semester class test, written in August. The essay, which had a thousand-word limit, required that students explain the role and significance of the branch of law known as Administrative Law, while the tests sought to assess students' understandings of a series of readings. The essay was completed by the students in their own time at home. Marking criteria were provided with an explanation of the assignment task and the essay was graded by postgraduate tutors whose marks were moderated by the course lecturer [see Appendix 1]. The tests were written under examination conditions in a 45-minute class. This was the sixth test which the students had written over a period of two semesters. The assessment sought to measure students' understandings of a series of readings. The application of four themes, contained in a series of four stories, to various hypothetical factual scenarios formed the main focus of the test [see Appendix 2].

Twelve students who were participants in an academic development programme (ADP) in a South African Law Faculty volunteered to participate in the study. The ADP aims at redress for previously disadvantaged students in higher education. Of the twelve students, six were undergraduate students, while the other six were graduates who had already obtained a degree in a faculty other than law. Six students had English as their first language, while the other six had English as an additional language (EAL). The reason for selecting students in such a programme was because these students receive extensive support in the development of legal writing skills throughout their first year. This support is provided by means of explicit teaching regarding the conventions of legal writing and extensive written and oral feedback on their weekly submissions. The placement of undergraduate students on the ADP was based on their results in the National Senior Certificate (NSC) combined with their mark achieved in the National Benchmarking Tests (NBTs), while postgraduate students' grade point average in their primary degree was a determinant factor. In both cases, these students fell into a band of points below the minimum admission criteria for students admitted to the mainstream class.

Prior to the textual analysis, we had interviewed the students twice on their perceptions of their challenges with legal writing as well as on their overall induction into the faculty. Semistructured interviews with each of the students were conducted at the beginning of the year and follow-up interviews were conducted at the end of their first year. In both these interviews we asked students to describe their understandings of what constitutes legal writing, as well as the challenges they encountered in their writing. In the first interview, students addressed these questions in relation to a marked essay from one of their courses. In 
the second interview, the question regarding students' perceptions of their struggles in the faculty was revisited with the aim of assessing the nature and extent of their development in engaging with the literacy practices of Law. The data from these interviews reflected how the undergraduate and postgraduate students perceived their struggles as being mainly in engaging with legal concepts, reading effectively, and with incorporating legal sources and cases in their writing in a manner deemed appropriate by the discipline [see Ngwenya (2010) who highlights similar challenges experienced by first-year Law students at a historically black South African university]. In some instances, the EAL students from both groups linked these challenges to the fact that they did not have English as a first language. Guided by this interview data, in this article we undertake a descriptive discourse analysis (Gee, 1999) which examines individuals' use of discourse at the levels of content, concept and language (Lung, 2006). Our analysis thus focuses on their use of discourse at the sentence level (lexicogrammar), on the intertextual aspects of their writing in their engagement with legal content in the form of prescribed material in their arguments, as well as on their use and understanding of legal concepts.

\section{THEORETICAL FRAMEWORK}

\subsection{An English for Specific Purposes Approach to genre}

In analysing our research participants' textual practices and the recommendations for teaching which emerge from this analysis, we acknowledge the value of a genre-based pedagogy and within that the English for Specific Purposes approach to genre. A genre-based pedagogy calls for the explicit teaching of the form of key genres as well as the linguistic choices which are available to writers in particular contexts. The focus of context in genre-based pedagogies is best expressed by Hyland (2007:9) when he states that "[w]riters are always influenced by the social activity they are engaged in... their choices of grammar, vocabulary, content and organization therefore depend on the situations in which they are writing..." The English for Specific Purposes (ESP) approach to genre focuses on how speakers of English as a second language negotiate the structural and linguistic aspects of key genres in academic and professional contexts and how their engagement with these genres can be facilitated through the relevant pedagogic practices. Using an ESP approach to genre, however, does not allow us to explore students' own perspectives of their literacy practices - a process which is made possible by an academic literacy approach.

\subsection{An academic literacies approach to genre}

An academic literacies approach to writing seeks to understand the meanings which student writers attach to their acts of reading and writing as they are inducted into a specific discipline. This approach, as advocated by NLS theorists such as Gee (1996) and Street (1995), sought to challenge autonomous views of literacy which were largely decontextualised and which tended to focus only on its cognitive aspect. In contrast, an academic literacies approach views literacy as multiple and as situated in the generic practices constituting particular learning contexts. 
Our analysis is based on Gee's (1996) notion of Discourse. In describing individuals' participation in the social practices of a particular context, he refers to specific ways of talking, thinking, valuing and being. In a more recent publication, Gee (2010:20) extends this description of Discourse when he maintains: 'People do not just read and write in general, they read and write specific sorts of 'texts' in specific ways; these ways are determined by the values and practices of different social and cultural groups'. The discourse analysis we conducted then allowed us to gauge the extent to which students exhibited an awareness of the law discipline's practices through the discursive and linguistic choices they made in their writing. In illustrating how the discourse of a particular social setting shapes the use of language, content and concept, Lung (2006) maintains that concept, which she defines as an abstract idea, permeates content - 'the material or substance of a writing' (2006:301-302) as well as language. This implies, as our analysis will show, that the three intersect significantly and affect each other in very direct ways. In the next section, we present the findings yielded by our textual analysis. We begin with a consideration of the struggles experienced by our research participants at the level of lexico-grammar. In the discussion below, we refer to individual students by using pseudonyms Frank, Farah, Inbal, Imraan, Langa, Olwami, Sam, Yolanda and Yusuf.

\section{FINDINGS}

\subsection{Lexico-grammatical analysis}

Our analysis indicated that most of the students struggled with everyday grammar use in general as well as with legal discourse in particular. This struggle was evident in their (mis)use of prepositions and definite articles, as well as in their use of the appropriate tense to distinguish between facts which constitute past events, and current texts and legislation which constitute the present.

\subsubsection{Preposition and article use}

Students' struggles with lexico-grammar manifested in their (mis)use of prepositions, a problem which was highlighted in the feedback from their markers (see also Greenbaum \& Mbali, 2002:239). The following examples illustrate this struggle: there was discrimination against (on the basis of) race and class; to limit it would mean to leave it at (unnecessary preposition) where it is at; the distinction of (between) law and politics; instil the values of the Constitution at (in) the hearts of all; strict compliance to (with) court orders; in (under) the present government; and courts' review on (of) administrative action.

Their struggles with lexico-grammar also extended to their use of definite and indefinite articles. Students' struggles with these can be classified in terms of struggles with the indefinite article, struggles with use of the definite article and, lastly, problems with zero article where they included articles where there should have been none. The following paragraph captures all three struggles. In this paragraph, Frank, an undergraduate second language speaker of English, was writing about changes in Administrative law since 1994: 'They spoke...about the Constitution being the transformative document,' 'the constitutional section of (the) equality clause,' 'the parliament', 'an incident of (he $)$ separation of powers' 
(doctrine); 'administrative law in (the) post 1994' (dispensation) as well as 'the basis of judicial review requires the (should be an) understanding of the constitutional framework.' Such errors may be attributable to the students' EAL status, since the indefinite and definite article present particular problems as there is no distinction between the two in most African languages. Gough (1996:3), for instance, identifies the omission of the indefinite article as a feature of African English.

\subsubsection{Tense usage}

The correct use of tenses presented itself as a challenge to many of the students, particularly in their descriptions of the facts of legal cases, for which, by convention, the past tense is used. In contrast, when relating statements taken from a reading it is usual to use the present tense if it is a current piece of writing. Examples such as "the court says..." and "the author argued..." were identified as being problematic by the marker. There was also evidence of a tendency to use the past continuous tense instead of the past perfect tense in explaining how the law functioned. Minow (2012:2) refers to this feature of Black South African English as "the use of the progressive aspect". She elaborates on this by stating that the "ing construction" is frequently used by African speakers when expressing past habits. A paragraph from Sam's writing illustrates both these instances of tense usage. In his test, Sam commented: "the last obstacle was the narrow patriarchal Nationalist mindset that society was revealing when they categorised people and put them in the category of 'the other'". The use of the past continuous tense here, "was revealing", is inappropriate and should have been replaced by the past perfect form of the verb, namely "revealed". Although the level of sophistication in Sam's writing appeared to have improved significantly at this point in his vocabulary usage, it seems likely that he was employing terms used in the original text. In addition to the struggles with using the appropriate lexico-grammatical structures in their writing, the students' writing also exhibited struggles with style and idiom use.

\subsection{Struggles with style}

The students' struggles with style were evident in the colloquial expressions they used in their arguments.

\subsubsection{Colloquial expressions}

Both the undergraduate and postgraduate students' writing exhibited an inability to distinguish between formal and informal writing. For example, one of the postgraduate students, Farah, used a number of colloquial expressions in her explanation of four stories from one of the readings. These stories were used as vehicles to reveal differing facets of the theme of how the law can be used as a tool by different constituencies, such as the executive and the judiciary, to achieve a degree of oppression of marginalised groups.

In describing the events during a labour revolt when the Law was used as a means to repress opposition to the executive, Farah wrote:

Story two points out that there were lawyers going against the grain. In story two the relationship between the law and politics was displayed. Long had been on trial for the 
murder of a spy on the Rand (at the time there was a revolt at Fordsburg). Long had two trials, in the second trial Long was sentenced to death. The judiciary had said Long should apply for mercy to the Royal Lord.

The conversational tone in which she wrote was evident in her choice of lexical items. For example, her use of the verb 'points out' instead of the more formal 'indicates' as well as 'said' instead of 'held' or 'stated' illustrates this problem. Like Farah, Yusuf used informal language in a number of instances in his test answer, such as in the following extract: '.. judges used the superior Roman-Dutch law... and found in favour of the white guy'.

In the next section we discuss how students' struggles with integrating the content into their arguments manifested as a challenge with an accurate selection of relevant content as well as an inability to discern between what is taken for granted as constituting tacit knowledge within the discipline and that which should be made explicit.

\subsection{Analysis of students' engagement with content}

\subsubsection{Identifying salient information in prescribed readings}

In the first part of this section we show how students' struggles to engage with prescribed legal content was evident in their inability to identify those sections of their readings which conveyed the main points and those sections which merely served to illustrate these main points, as well as their inability to understand how the different sections of their readings fit together to form a coherent whole.

The students' test answers reflected a focus on the narrative details of the four stories contained in a prescribed reading. This meant that the manner in which they engaged with these stories failed to capture the more abstract ideas therein. Farah, for example, began her answer by giving a detailed discussion of each story, incorporating what her marker referred to as 'simplistic facts' in her feedback. The feedback at the end of her answer summed up this shortcoming: 'Please read $\mathrm{C}$ (author) again and try to summarise the themes accurately and in a more analytical way'. Abdul, who had vividly described his challenges with reading in the interviews, included irrelevant sections of the reading, which were unrelated to the question. While this could have been due to not fully understanding what the question required of him, it also reflected a lack of understanding of how the stories functioned to demonstrate central themes.

\subsubsection{Precision in presenting content}

In the previous section we made the point that students are not selective in content, possibly because they were failing to grasp the main thrust of the readings. In this section we show how students struggled to express their ideas. Students struggled to present the content with the precision valued in legal writing, a challenge which they had mentioned in their interviews. Instead of presenting concise statements, the students tended to express a single point through a detailed narrative. The novice writers revealed their unfamiliarity with this practice by using sentences of five to six lines in length. In his essay, for example, Langa wrote: "Transformative constitutionalism, as described by Justice L, is a continuous "staying on the bridge," it is an ongoing transformation, that aims to achieve substantive equality 
including socio-economic transformation and a shift in legal culture, going toward a culture of justification, all of which must be based on the values of the Constitution.' The main point he wanted to express was that the new Constitutional dispensation is a progressive project that aims to achieve substantive equality, socio-economic transformation and a shift in legal culture.

\subsubsection{Tacit knowledge}

The novice status of the texts produced by the students was also evident in their lack of an appreciation of what constitutes tacit knowledge within the discipline, resulting in students stating what a legal reader would consider trite or obvious. Examples of this were: 'Judges who are extremely powerful and who were not elected by the people will be constrained... which means that their freedom to do whatever they please in terms of legislation and laws, is limited' (Sam). It is hardly necessary to state that judges are extremely powerful, as a legal reader would be familiar with this notion. Similarly, a reader would know that judges are not elected by the people. Sam's explanation of what is meant by the term "constrained" is another example of his stating what is unnecessary.

In explaining some of the systemic challenges to transformation in South Africa, Yolanda wrote: "South Africa has a patriarchal nationalist society. By "patriarchal" (she, the author) means that we still live in a male-dominated society. Women are still seen as inferior and violence against women is still a problem. Secondly, L (author) looks at the socio-economic disparities in wealth, in that many people are still poor and struggling.' Her defining of the notions of 'patriarchy' as well as 'socio-economic disparities' is superfluous, in that a legal reader would understand the implications of the use of these terms.

There was also a tendency not to illustrate the links between the facts as outlined in the stories and the underlying themes, as well as instances where central terms were not explained or elaborated on. This pointed to a lack of a thorough understanding of the content. A number of 'what' and 'why' questions were evident in the marker's feedback, such as in instances where the marker encouraged students to support their claims with reference to recognised authorities.

The postgraduate students' essays similarly reflected their novice status and lack of understanding of what counts as crucial information. In his essay, Yusuf wrote: 'Story 2 involved the conviction of a certain individual by the name of Long'. The underlined section of the statement was bracketed and labelled as 'unnecessary' by the marker. This lack of precision signalled the participants' extensive struggles with legal discourse.

In the last section of our analysis, we illustrate various struggles which students encountered in engaging with legal concepts. As stated in our methodology, the notions of concept and content are interlinked (Lung, 2006). This is evident in the challenges experienced by the students, where struggles to effectively draw on legal content negatively affected their presentation of key concepts and vice versa. This means that some of the struggles which students had in engaging with legal concepts were as a result of an inappropriate use of legal sources such as legal cases. 


\subsection{Students' engagement with legal concepts}

The essay on Administrative Law required the students to actively engage with the legal concepts of 'lawfulness', 'procedural fairness' as well as 'reasonableness'. As part of this engagement, they were required to substantiate whatever points they presented in relation to these concepts with relevant cases. Our analysis reflects how both undergraduate and postgraduate students struggled to link these concepts to relevant cases in order to illustrate their use. Olwami, a postgraduate student, provided a fairly persuasive discussion of the concept of 'reasonableness'. He began his discussion by locating the concept within an appropriate context which illuminated its meaning. However, in attempting to link it to relevant legal cases, he drew on two cases without any elaboration of how these cases demonstrated its use. Moreover, in most of his paragraphs he failed to provide references for his statements, effectively overlooking the discipline's knowledge-validation practices.

The undergraduate students also struggled with legal concepts in their writing. Frank's general inability to communicate his ideas effectively resulted in confusion in his explanations of concepts. An example of this is where he attempted to explain the distinction between the application of Administrative Law prior to 1994 and its application after 1994. He wrote:

'In pre 1994 South African government, I can say that administrative actions were fair on that era, but if I can justify them with the present constitution, I can conclude that they were procedurally unfair and unreasonable.'

The meaning of his explanation is obscured by his inability to express his understanding in clear and appropriate language, once again demonstrating Lung's (2006) notion of the interlinking of language and concept. Moreover, it is worth noting that expressing a comparison is more difficult than talking about a single issue, even in everyday discourse.

Yolanda's essay, in turn, contained a succession of quotations from judgments and text books, suggesting that she has not adequately grasped the concepts relating to Administrative Law and was therefore unable to synthesise the ideas from various sources into a coherent explanation. The following three sentences in her essay are all extracted from the prescribed textbook:

Administrative law is a branch of law that governs and deals specifically with the administration of a country (footnote 1). Prior to 1994 administrative law developed within a system of parliamentary sovereignty (footnote 2). The courts were not allowed to enquire whether actions by the state administration were for public benefit or for the benefit of private persons (footnote 3 ).

This pattern of stringing together a series of paraphrased extracts from the textbook continued throughout her essay. Williams (1991:12) refers to this feature of novice students' writing as 'a deference to authority... writing as mere summary, without any analysis, copious quotes and stating what is self-evident.' 
In contrast, Imraan was able to use a quotation as a springboard for his own synthesis of ideas from a variety of sources as is evident in the first paragraph of his essay:

Administrative law... occupies a special place in our jurisprudence... (footnote). It is that part of law, governed by constitutional values and principles, which allows persons in public power to carry out and enforce existing laws enshrined in the constitution, and made by the legislature... There has been a significant change in the regulation of public power because of the shift from parliamentary sovereignty to constitutional supremacy.

He was able to incorporate into his essay a number of different sources, alternating direct quotes with paraphrasing, with references. His grasp of the concept of administrative law shows a thorough understanding which allowed him the flexibility to express aspects of the concept in his own words.

The struggle with concepts was also evident in how students failed to clearly illustrate the links between the concepts under discussion. The feedback provided on Inbal's essay, for example, commented on the structure of her assignment, suggesting that she make more effective links in her discussion of the concepts of 'lawfulness' and 'procedural fairness'. This resonates with the view of Mitchell (1998:277) when he comments that 'Legal writing implies awareness by the writer of analytical schemata.' Inbal's writing lacked the coherence required to develop a cogent argument in law in that it contained disjointed pieces of information, without the necessary linkages in terms of the ideas under discussion within them. At the end of the essay, the marker again questioned the relation between concepts. While Inbal had been able to define these concepts, she had failed to show their interrelationship in context along with the necessary references to authoritative sources.

\section{CONCLUSION}

The various challenges which the students experienced in engaging with the aspects of discourse discussed in this article are captured in Williams' (1991:12) observation that novice legal writers focus on concrete rather than abstract thinking and are unable to manipulate abstract legal principles. It seems that students lacked a thorough understanding of the ways in which the sources on which they drew could be utilised to elucidate their arguments. Their struggle with legal concepts also had implications for their overall engagement with the content. In cases where students were able to define key concepts appropriately, they often neglected to extend this definition to illustrate their practical application and to situate them alongside the discipline's theories.

The analysis also reflects how the difficulty with reading, which students identified as a challenge within Law, manifested in their writing. A combination of various strategies, directed at engaging students as active learners in the construction of knowledge, would address some of the literacy challenges identified in this article. As espoused by the ESP approach to genre teaching, the explicit modelling of critical reading strategies and the explicit teaching of effective summarising skills, as well as practice in close textual analysis using guided questions to identify key points in readings within the discipline would be 
instructive for students at the beginning of their legal studies. A more explicit focus on discourse practices, embedded within course materials and taught in small group settings, as well as additional practice of legal writing with feedback to students, would require the allocation of resources as well as the creation of spaces within a generally heavily contentdriven curriculum in law subjects. Improved training of tutors, who could then assist with the teaching of legal writing conventions to even smaller groups and with the provision of much more detailed feedback on a regular basis to the students on their writing, would require the further deployment of resources if these problems are to be effectively addressed. Some pragmatic options would be to offer workshops, where modelling of textual analysis could be demonstrated to larger groups of students in an interactive setting. Samples of legal writing of varying quality on which students could comment could be provided for a class. After this students could be given copies of actual feedback comments, given by an expert legal reader, to assist them to appreciate features of legal writing that are central to legal discourse.

In order to reach more students by means of a cost-effective online medium, cloze tests, or gap-filling exercises, to reinforce the acquisition of 'terms of art' and the appropriate use of prepositions and the in/definite article within the context of legal materials, could be created (Greenbaum \& Mbali, 2002). The design of online multiple choice questions which students could undertake in their own time, with explanatory answers, would support the acquisition of concepts by novices. A self-reporting mechanism, allowing students to practice the exercises repeatedly until they achieve a level of mastery, could be developed so that students would be engaged in self-directed learning to improve their basic legal writing skills and conceptual understanding. We believe that these strategies would provide increased opportunities for students to actively engage in improving their acquisition of writing skills, as well as for the addressing of wider issues around the teaching and learning within the faculty and the quality of graduates produced therein.

\section{REFERENCES}

GEE, JP. 1996. Social linguistics and literacies: Ideology in Discourses. London: Taylor \& Francis.

GEE, JP. 1999. An Introduction to Discourse Analysis: Theory and Method. USA: Routledge.

GEE, JP. 2010. New Digital Media and Learning as an Emerging Area and "Worked Examples" as One Way Forward. Cambridge, Massachusetts: MIT Press.

GOUGH, DH. 1996. English in South Africa. Introduction to the Dictionary of South African English on Historical Principles. In Silva, P (Ed), Dictionary of South African English on Historical Principles: Oxford University Press.

GREENBAUM, L \& MBALI, C. 2002. An analysis of language problems identified in legal writing by low achieving first-year students, with some suggestions for remediation. Southern African Linguistics and Applied Language Studies, 20(4):233-244.

HOWE, PM. 1990. The problem of the problem question in English for academic legal purposes. English for Specific Purposes, 9 (3):193-273. 
HYLAND, K. 2007. Genre and second language writing. Ann Arbor: University of Michigan Press.

LUNG, J. 2006. Applied Genre Analysis: Cases in Business and Law. PhD thesis. City University of Hong Kong.

MAURER, NM \& MISCHLER, LF. 1994. Introduction to lawyering: Teaching first-year students to think like professionals. Journal of Legal Education, 44 (1): 96 -115.

MINOW, V. 2012. 'I am going to the office every day: The -ing construction in Black South African English.' Paper presented at Symposium: The Pragmatics of Aspect in Varieties of English, 16/17 April, Innsbruck, Austria. Available: http://www.ubk.ac.at/anglistik/symposium2012/symposium-innsbruck.pdf

MITCHELL, JB. 1989. Current theories on expert thinking: A full faculty considers the implications for legal education. Journal of Legal Education, 39:275-297.

NGWENYA, T. 2010. Correlating first-year students' profile with the language demands of their content subjects. Per Linguam, 26(1): 74-98.

SOUTH AFRICAN PRESS ASSOCIATION (SAPA). Law graduates 'can't handle figures or write papers'. The Cape Times. 4 April 2007.

SOUTH AFRICAN PRESS ASSOCIATION (SAPA). LLB report urges numeracy, literacy training. The Times, 6 July, 2012.

STREET, B. 1995. Social Literacies. London: Longman.

WILLIAMS, J. 1991. On the maturing of legal writers: Two models of growth and development. Journal of the Legal Writing Institute, 1(1):1-31.

\section{BIOGRAPHICAL NOTE}

Bongi Bangeni is a senior lecturer in the Centre for Higher Education Development's Academic Development Programme at the University of Cape Town. Her areas of interest include the development of a disciplinary identity in novice writers and the ways in which student writers experience the transition from undergraduate to postgraduate studies.

Email: Abongwe.Bangeni@uct.ac.za

Lesley Greenbaum is a senior lecturer in the Private Law Department of the Law Faculty at the University of Cape Town. She is convenor or the Law Academic Development Programme. Her areas of interest include legal writing, students' acquisition of legal discourse and effective teaching methodologies in the discipline.

Email: Lesley.greenbaum@uct.ac.za 


\section{APPENDIX 1 \\ TUTORIAL ASSIGNMENT 2: Due: Thursday, April $28^{\text {th }}$}

$\underline{\text { Required Reading }}$

Kate O'Regan 'Breaking ground: some thoughts on the seismic shift in our administrative law' (2004) 121 SALJ 424.

Hugh Corder 'Without deference, with respect' (2004) 121 SALJ 438.

Write an essay of not more than 1000 words on the following topic (you must include your word count at the end of the essay):

'Whilst there is no bright line between public and private law, administrative law, which forms the core of public law, occupies a special place in our jurisprudence. It is an incident of the separation of powers under which our courts regulate and control the exercise of public power by the other branches of government. It is built on constitutional principles which define the authority of each branch of government, their interrelationship and the boundaries between them...'

Chaskalson P in Pharmaceutical Manufacturers' Association of SA: In re Ex parte President of the Republic of South Africa 2000 (2) SA 674 (CC) at para 45.

Critically evaluate the claims made in the above statement in light of the role that the courts play in applying administrative law.

You should include in your argument:

- A brief historical review setting the context for the current approach to administrative law;

- a careful analysis of the relevant provisions of the Constitution, and in particular s33;

- your opinion on the role of administrative law in regulating the exercise of public power, in relation to the separation of powers doctrine, ensuring that it is substantiated with reference to case law or other reliable sources.

Ensure that you use correct referencing styles (according to the Writing Guide on the Law Library website) and that all sources are adequately acknowledged.

Marking Criteria:

Content (identifies main points, make relevant points, understands key concepts, substantiates points with reference to cases or readings)

Structure (well planned and organised, coherent development of argument)

Expression and presentation (clearly articulated ideas, acceptable grammar and spelling, 


\section{APPENDIX 2}

\section{ADP Test: Developing a Legal Culture in South Africa}

\section{Friday, $5^{\text {th }}$ August}

\section{Time: 45 minutes}

Marks: 20

\section{WRITE A PARAGRAPH ON EACH OF THESE TOPICS.}

1. Describe the key themes that link the four different stories in Chanock's chapter. (10 marks)

2. In the context of late 1970s, what does Dugard say judges should have done in civil liberty cases:

(i) where a statute was ambiguous in its meaning?

(ii) where a statute was unambiguous in its meaning? (10 marks)

TOTAL MARKS: 20 